\title{
Thermal regime for convective drying products
}

\author{
Shavkat Imomov $^{*}$, Khurram Nuriddinov ${ }^{1}$ and Otabek Nuriddinov \\ Bukhara branch of the Tashkent Institute of Irrigation and Agricultural Mechanization \\ Engineers, Bukhara, Uzbekistan
}

\begin{abstract}
In the work, the specified features of the temperature regime in the drying chamber showed that when the coolant moves in the chamber, both the temperature and humidity regime of the air and the temperature and drying rate of the product change, and the drying rate is almost proportional to the increase in air humidity. Based on the studies carried out, simplifications were obtained in describing the drying process, which makes it possible to more reasonably carry out engineering calculations in the design of the dryer, in particular, to set the input and output air humidity, to determine the length (or height) of the drying chamber.
\end{abstract}

\section{Introduction}

The results of experimental studies of the process of the essence, the features of drying various products in the chamber and the open air are considered. The dependences of the drying rate of these products on the drying temperature are determined. The data obtained is one of the main components required for calculating and designing the drying plant as a whole or its individual elements.

The paper presents a method for calculating the drying rate and its change along the length of the chamber. However, this example does not consider the change in the moisture content of steam in the air and its effect on the drying rate. It can be noted that at present, when calculating the thermal parameters of the dryer, the balanced equation of the formula is used in which the productivity (or the average drying rate) and air parameters (temperature and humidity) are set at the inlet and outlet of the dryer. As a result of the calculation, the mass air flow and the heat required for drying are determined [1-4]. To determine the overall dimensions of the dryer, the drying time of the product or the drying rate and its dependence on time must be known. Moreover, the drying rate is a function of the moisture content, which is also variable along the length (height) of the chamber. In this regard, to analyze the issue, consider the problem of changing the drying rate of the product along the length (height) of the chamber (see Figure 1).

\footnotetext{
* Corresponding author: shavkat-imomov@rambler.ru
} 


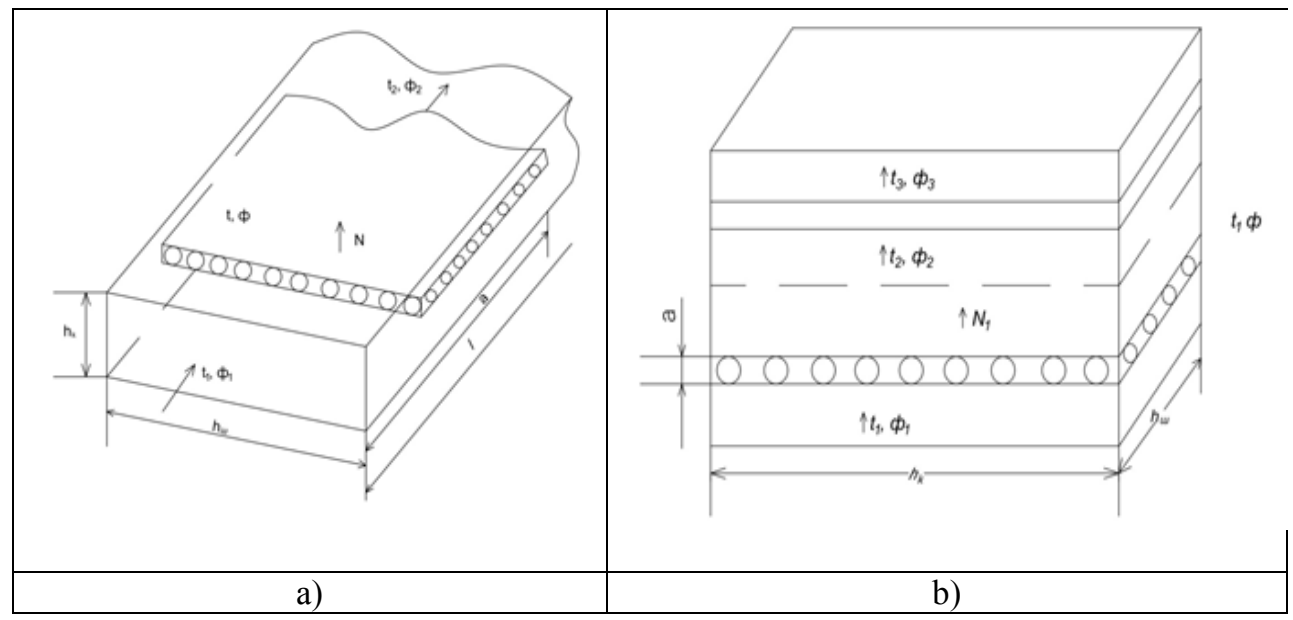

Fig. 1. To the determination of the drying speed in the horizontal (a) and vertical (b) drying chambers.

\section{Materials and Methods}

Let's first consider a horizontal camera [11-14]. We will solve the problem under the following conditions - a chamber of length 1 is divided into sections of length $\ell$ a within which the parameters of air and product are constant. The dimensions of the chamber are also given (see Fig. 1a, b). A diagram for determining the temperature and humidity conditions of the dryer in individual sections is shown in Figure 2.

In the section $O$ this temperature $t_{0}$, and humidity $\varphi$ ambient air.

In the section I - heater, temperature given $t_{1}$, and air speed $\omega_{1}$.

Based on these data, we determine the saturation pressure of water vapor $P_{N_{1}}$ at $t=t_{1}$ in the formula [3].

$$
P_{N}=\exp \left(\sum_{i=-1}^{i=1} a_{i}\left(\left(\frac{t+273}{1000}\right)^{i}+Q_{2} \cdot \ln (t+273)\right)\right.
$$

Further, given that the partial pressure of steam in section $\mathrm{I}$ is equal to the partial pressure of steam in the ambient air $P_{\Pi_{1}}=P_{\Pi_{0}}$

determining humidity $\varphi$ heated air in the area I.

$$
\varphi=\frac{P_{P}}{P_{N_{1}}}
$$

and moisture content of water vapor in the air $d_{1}$

$$
d_{1}=0.622 \frac{P_{P_{1}}}{B-P_{P_{1}}} \quad t_{k}, \varphi_{k}
$$

where $B$ is barometer pressure $\left(B=10332 \frac{\mathrm{kg}}{\mathrm{m}^{2}}\right)$.

Finding the amount of heat $Q_{1}$, airborne before entering the site $a$.

$$
Q_{1}=G_{1} \cdot C_{p} \cdot\left(t_{1}-t_{0}\right) \cdot \Delta \tau
$$




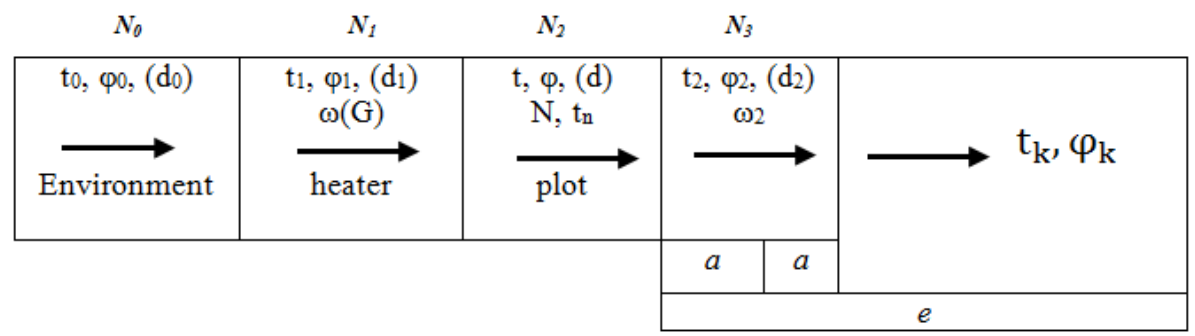

Fig. 2. Scheme for calculating the temperature and humidity conditions, drying rate and heat fluxes along the length of the horizontal drying chamber

where $G_{1}$ is mass waste and $C_{p}$ is heat capacity of air.

Time $\Delta \tau$ determining from speed $\omega_{1}$ and section length $a$.

$$
\Delta \tau=\frac{a}{\omega_{1}}
$$

Mass waste air is equal

$$
G=\omega_{1} \cdot \rho \cdot h_{k} \cdot h_{s h}
$$

Where $\rho$ is air density and $h_{\mathrm{\kappa}}, h_{\mathrm{\omega}}$ are height and width of the cross-section of the chamber. We now turn to the initial section of the dryer a. Let us here know the drying rate of the product $N$, then the amount of evaporated moisture $m_{\Pi}$ during $\Delta \tau$ is equal

$$
m_{p}=N \cdot S_{p} \cdot \Delta \tau
$$

A the amount of heat for evaporation $Q_{a v r}$ is equal

$$
Q_{a v p}=m_{p} \cdot r
$$

On the other hand, it should be equal to the amount of heat transferred by air to the product.

$$
Q_{\alpha}=\alpha \cdot S_{p} \cdot\left(t-t_{p}\right) \cdot \Delta \tau
$$

where $S_{\text {п }}$ is surface area of product

$$
S_{p}=a \cdot h_{s h}
$$

As you know, in a stationary mode, especially at the first and second stages of drying, the condition

$$
Q_{\text {avp }}=Q_{\alpha}
$$

This condition makes it possible to link heat and mass transfer processes in the dryer. However, this equation is inconsistent (two unknowns). Therefore, taking into account that at the first and partially at the second stage of drying, the product temperature will be equal to the temperature of the wet thermometer, the problem of determining the parameters in section a will be solved as follows [15-22]. As a first approximation, we assume that the air temperature $t_{\mathrm{B}}$ in the section $a$ equal to the inlet air temperature. Then, in principle, it is 
determined by the length of the section - $a$, with a decrease in the length of the segment a, this condition will obviously be satisfied more precisely. Then from the formula Shprung

$$
P_{p}=P_{N P}-6.78 \cdot\left(t-t_{n}\right) \frac{P}{10270}
$$

With an error not exceeding 3-4\%, the product temperature can be determined based on the iterative solution $t_{n}$. Formula (8) and the balance formula implies that if given $N$ initial, then we can for a given $\alpha_{k}$ determine the amount of heat $Q_{2}$, carried by the air leaving the sitea $a$ and its temperature $t_{2}$, or

$$
Q_{2}=Q_{1}-Q_{a v p}-Q_{k}
$$

Where $Q_{\mathrm{K}}$ is heat loss from the camera to the environment at the site.

$$
Q_{k}=\alpha_{k} \cdot S_{k} \cdot\left(t-t_{0}\right) \cdot \Delta \tau \approx 2 \cdot \alpha_{k} \cdot S_{p} \cdot\left(t-t_{0}\right) \cdot \Delta \tau
$$

Substituting into values $Q_{1}, Q_{a b r}, Q_{k}$, we get

$$
Q_{2}=\left(\omega_{1} \cdot \rho_{1} \cdot h_{k} \cdot h_{s h} \cdot C_{\mathrm{p}} \cdot\left(t_{1}-t_{0}\right)-r \cdot N \cdot a \cdot h_{s h}-2 \alpha_{k} \cdot a \cdot h_{s h}\left(t-t_{0}\right)\right) \Delta \tau
$$

Considering that the mass air flow is constant, i.e., $G=G_{1}$ get

$$
\begin{gathered}
t_{2}=\frac{t_{0}+Q_{2}}{G_{1} \cdot C_{\mathrm{p}} \cdot \Delta \tau} \\
\text { or } \quad t_{2}=t_{0}+\frac{\left(\omega_{1} \cdot \rho_{1} \cdot h_{\mathrm{K}} \cdot C_{\mathrm{p}}\left(t_{1}-t_{0}\right)-N \cdot r \cdot a-2 \cdot \alpha_{\mathrm{K}} \cdot a \cdot\left(t_{1}-t_{0}\right)\right) \cdot h_{\mathrm{U}}}{\omega_{1} \cdot \rho_{1} \cdot h_{\mathrm{K}} \cdot h_{\mathrm{U}}}
\end{gathered}
$$

Thus we determine temperature of $t_{2}$ air out from section $a$. At the exit from the a, we already have other humidity $\varphi$ and as a result of this, the drying speed will also change in section $2 N_{2}$. In general, the drying rate is determined by both the temperature of the drying agent and its moisture content. The dependence of the drying rate on temperature for a number of products was obtained by us above [20, 23]. The indirect dependence of the drying rate on humidity and air temperature can be determined from the Dalton formula, which is valid for the rate of evaporation of water from a free surface. With sufficient reason, this formula can be used in the first and second stages of drying, when it is considered that the surface of the product is covered with a continuous water film. We write down Dalton's formula in the form:

$$
N=C \cdot(H-h), \frac{g}{m^{2} \cdot h}
$$

where $C$ is coefficient evaporation, dependent on speed of air;

$H$ is vapor saturation pressure at the water surface at wet bulb temperature (product temperature) and $h$ is partial vapor pressure in air [4]. Using Sprung's formula (12), (17) can be rewritten as

$$
N=C \cdot 6.78 \cdot\left(t-t_{n}\right) \frac{P}{10270}
$$


From (17), (18), the dependence of the evaporation rate $\mathrm{N}$ on the temperature and humidity of the air (included in $\mathrm{h}$ ) is clearly visible. Coefficient $\mathrm{C}$ according to [4] can be represented as:

$$
C=(172.2+130.8 \cdot \omega) \cdot 10^{-3}, \frac{\Gamma}{m^{2} \cdot h \cdot \frac{k g}{m^{2}}}
$$

So, to determine the drying parameters in the second section, we also need to know the speed of the coolant $\omega^{2}$ and the partial pressure of vapor in the air $P_{p_{2}}$.

Considering that $G_{1}=G_{2}$, we get

$$
\omega_{2}=\omega_{1} \cdot \frac{\rho_{1}}{\rho_{2}}
$$

Determine $P_{\mathrm{I}_{2}}$. During exit in the section 2 we know that $t_{2}$ and $d_{2}$

$$
d_{2}=d_{1}+\Delta d_{1}
$$

Where

$$
\Delta d_{1}=\frac{m_{p}}{\rho_{v} \cdot V_{v}}
$$

where $V_{\mathrm{B}}$ is volume of air in a separate area in which moisture $m_{p}$ has evaporated from the product. $\left(V_{v}=h_{k} \cdot h_{s h} \cdot a\right)$, at values $\omega_{v} \mathrm{~m} / \mathrm{c}$,

$$
d_{2}=d_{1}+\frac{N_{1} \cdot h_{s h} \cdot a \cdot \Delta \tau}{\omega_{1} \cdot h_{s h} \cdot h_{k} \cdot \Delta \tau}=d_{1}+\frac{N_{1} \cdot a}{3600 \cdot h_{k} \cdot \omega_{1}},\left[\frac{g}{\mathrm{~kg} \cdot \mathrm{sux}}\right]
$$

\section{Results and Discussion}

And from (3) we define $P_{p_{2}}$, and the parameters are calculated in the second section, then the process is repeated until leaving the camera. An example of calculating the change in temperature and humidity conditions in a horizontal chamber, with the following initial data: ambient air: $t_{0}=28^{\circ} \mathrm{C}, \varphi=55 \%$

air leaving the heater : $\omega_{1}=1 \mathrm{~m} / \mathrm{s} ; t_{1}=45^{\circ}$

parameters of the camera: $h_{\mathrm{K}}=0.1 \mathrm{~m}, h_{\mathrm{sh}}=0.5 \mathrm{~m}, a=1 \mathrm{~m}$

parameters of the products: $N_{1}=0,1 \frac{\mathrm{kg}}{\left(\mathrm{m}^{2} \cdot h\right)}$

Are shown in Figure 3. From figure $3 \mathrm{a}, \mathrm{b}$ it follows that for a given ratio of parameters the loss of heat by air in some areas is about $10 \%$ (not convection and evaporation), and there is a fairly strong change in the drying rate and moisture content of the product practically a decrease in the drying rate is proportional to the increase in air humidity. At the same time, it can be noted that the moisture content of water in the air, the saturation pressure of the vapor at the surface of the product and the speed of air movement in the chamber remain practically constant. Due to these features, the partial pressure of vapor in the air is also practically constant. The research carried out makes it possible to determine the length of the working section of the chamber and set the limits for changing the temperature and humidity conditions in the camera $[5,6]$. 

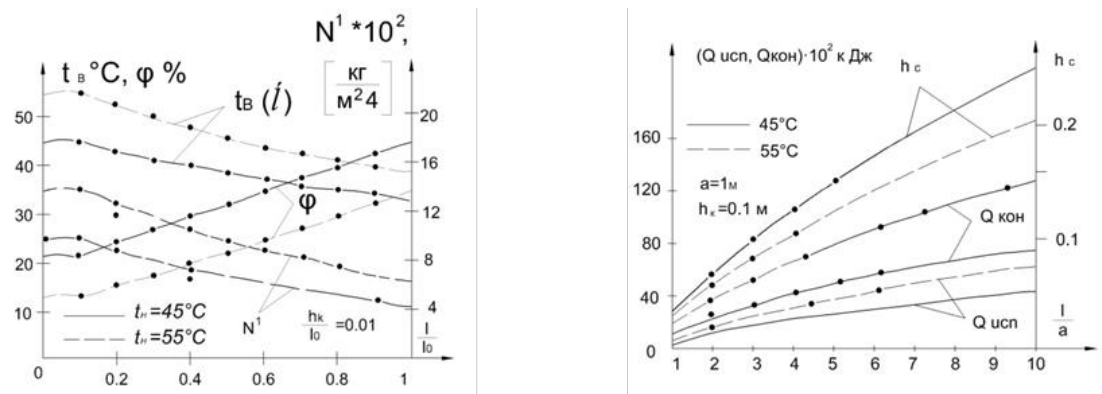

Fig. 3. Temperature and humidity conditions and distribution of heat fluxes along the length of the horizontal drying camera

The results of drying studies in a horizontal camera can be transferred to a vertical camera, provided they have the same loads.

It also follows from the analysis that the intensities of heat exchange processes in a combined dryer during convective drying with selected drying modes will not exceed 200 $\mathrm{W} / \mathrm{m}^{2}$, taking into account the heat loss by the chamber walls.

In this regard, it is of practical interest to consider when the upper wall of the horizontal camera is transparent to sunlight.

\section{Conclusion}

Studies of the heat balance and temperature regime in the drying chamber showed that when the coolant moves in the chamber, the temperature and humidity regime of the air, as well as the temperature and drying rate of the product, change, and the drying rate is almost proportional to the increase in air humidity. Based on the studies carried out, simplifications were obtained in the description of the drying process, which allow more reasonable engineering calculations when designing a dryer, in particular, to set the input and output air humidity, to determine the length (or height) of the drying chamber.

\section{References}

1. Nuriddinov X. Razrabotka i issledovaniye kombinirovannoy geliosushilki plodovoovoshchnoy produktsii, pp. 109-117, Tashkent, (1994)

2. Nuriddinov X., Kuchkarov J.J., Jurayev A.A., Normamatov Ch.K., Nuriddinov O.X. Teplovoy balans kombinirovannoy geliosushilki, Shkola Nauki, № 4 (15), p. 4, (2019)

3. Nuriddinov X., Kuchkarov J.J., Normamatov Ch.K., Jurayev A.A., Nuriddinov O.X. Teplovoy rejim pri radiatsionnoy sushke produktov, Shkola Nauki, № 4(15) pp.1-3, (2019)

4. Ginzburg A.S. Raschet i proyektirovaniye sushil'nyx ustanovok pishchevoy promyshlennosti, p.336, Moscow, (1985)

5. Kavetskiy G.D., Korolev A.V. Protsessy i apparaty pishchevyx proizvodstv, p. 432, Moscow, (1991)

6. Mysak S.V. Perfection of production technology fish with vegetables dry products, $\mathrm{p}$. 24, Krasnodar, (2007)

7. Karpenko V.Y. Development of technology of concentrates instant soups functional purposes of a fruit and vegetable raw, p. 24, Krasnodar, (2011)

8. Bocharov V.A. Perfection of of elements of technology drying of vegetables. p. 27, (2010) 
9. Maksyuta I.V. Development of technology for fish with vegetables dry products gerodieticheskogo destination, p. 24, Krasnodar, (2004)

10. Rakhmonov S., Umurzakov U., Rakhmonov K., Bozarov I., Karamatov O. Land use and land cover change in Khorezm, Uzbekistan. E3S Web of Conferences, 227, 01002, (2021)

11. Umurzakov U., Mamatov F., Aldoshin N., Mirzaev B. Exploration of tillage technologies in the Republic of Uzbekistan, IOP Conference Series, Earth and Environmental Science, 614(1), 012168, (2020)

12. Umurzakov U., and Djuraev B. Prediction of prices for agricultural products through markov chain model, International Journal of Psychosocial Rehabilitation, 24(3), pp. 293-303, (2020)

13. Umurzakov U., Mirzaev B., Salahodjaev R., Isaeva A., and Tosheva S. Energy consumption and economic growth: Evidence from post-communist countries. International Journal of Energy Economics and Policy, 10(6), pp. 59-65, (2020)

14. Matyakubov B., Begmatov I., Raimova I. and Teplova G. Factors for the efficient use of water distribution facilities. IOP Conf. Ser. Mater. Sci. Eng. 883, 012025 (2020).

15. Bazarov D., Vatin N., Obidov B., and Vokhidov O. Hydrodynamic effects of the flow on the slab of the stand in the presence of cavitation. IOP Conf. Ser. Mater. Sci. Eng. 1030, 012110 (2021).

16. Bazarov D., Markova I., Sultanov S. and Kattakulov F. Dynamics of the hydraulic and alluvial regime of the lower reaches of the Amudarya after the commissioning of the Takhiatash and Tuyamuyun hydrosystems. IOP Conf. Ser. Mater. Sci. Eng. 1030, 012110 (2021).

17. Bazarov D. and Vokhidov O. Extinguishing Excess Flow Energy in Spillway Structures. In book: Proceedings of EECE 2020, LNCE 150, pp. 535-545, (2021) DOI: 10.1007/978-3-030-72404-7_52

18. Bazarov D., Markova I., Norkulov B., Isabaev K., Sapaeva M. Operational efficiency of water damless intake. IOP Conf. Ser. Mater. Sci. Eng. 869(7), 072051, (2020)

19. Krutov A., Norkulov B., Mavlyanova D. Simulation of spreading of non-conservative passive substances in water bodies. IOP Conf. Ser. Mater. Sci. Eng. 883(1), 012028 (2020)

20. Shokirov B., Norkulov B., Nishanbaev Kh., Khurazbaev M., Nazarov B. Computer simulation of channel processes. E3S Web of Conferences, 97, 05012, (2019)

21. Shomayramov, M., Norkulov B., Rakhmanov J., Tadjiyeva D., Suyunov J. Experimental researches of hydraulic vacuum breakdown devices of siphon outlets of pumping stations. E3S Web of Conferences, 97, 05009, (2019)

22. Aghbashlo M. Measurement techniques to monitor and control fluidization quality in fluidized bed dryers, 32(9), pp. 1005-1051, (2014) 